\title{
Balance in children born prematurely currently aged 6-7
}

\author{
Ewa Dziuba ${ }^{1}$, Justyna Drzał-Grabiec ${ }^{1}$, Aleksandra Truszczyńska-Baszak², Katarzyna Guzek², \\ Katarzyna Zajkiewicz ${ }^{1}$
}

${ }^{1}$ Institute of Physiotherapy, University of Rzeszów, Rzeszów, Poland; ${ }^{2}$ Faculty of Rehabilitation, Józef Piłsudski University of Physical Education, Warsaw, Poland

\section{Summary}

Study aim: Premature birth is one of the major problems of obstetrics, leading to numerous complications that are associated with prematurity, for instance balance disorders. The aim of the study was to assess the impact of premature birth on the ability to maintain balance in children commencing their school education.

Material and methods: The study included children aged 6-7 years. The study group consisted of 59 children (31 girls and 28 boys, mean age $6.38 \pm$ SD 0.73 ) born prematurely between 24 and 35 weeks of gestation. The control group consisted of 61 children (28 girls and 33 boys, mean age $6.42 \pm 0.58$ ) born at term. The research utilized standardized test tools - one-leg openeyed and closed-eyed standing test, one-leg jumping test - and an original questionnaire survey.

Results: The children born at term achieved better results in the majority of tests. The comparison of girls and boys born prematurely and at term showed no statistically significant difference between them in terms of dynamic balance, static balance or total balance control. The comparison of the tests performed on the right and left lower limb in prematurely born children showed no statistically significant differences.

Conclusion: Premature birth affects the ability to maintain body balance. The results of the study indicate the need to develop coordination skills that shape body balance in prematurely born children.

Keywords: Child - Postural balance - Premature

\section{Introduction}

Around 15 million children are born prematurely each year around the world. According to the current data of the Central Statistical Office in Poland, in 2014, over 28,000 premature babies were born, which accounts for nearly $7.5 \%$ of all newborn babies. Premature birth is one of the major problems of obstetrics $[4,14]$. The development of medicine has made it possible to rescue children with low birth weight and severe complications resulting from prematurity. In premature infants, numerous health complications are diagnosed: retinopathy, hearing impairment, early brain injury with accompanying hypoxic events and ischemia $[4,23,27,30,31]$. They can adversely affect their development, including the balance system. In the period from birth to 7 years of age, there is an active increase in perceptual abilities and development of a sense of balance $[9,34,35]$. Equilibrium is the state of the postural system which is characterized by vertical posture obtained by balancing the forces affecting the body [33, 39]. According to some authors, it is the ability to hold the projection of the body mass center within the support surface estimated by the contour of the foot [33].

Full sensory integration is required for the proper functioning of the organism. Improvement of sensory integration happens mainly in the first seven years of life. The child gains a better image of the differentiation of his or her body and the surrounding world, as well as self-control, self-evaluation, and abstractive thinking. Learning and abstractive thinking do not appear automatically, but are the result of many years of evolution and processing of stimuli in the brain. Ayres distinguishes four levels of sensory integration, with their development progressing linearly, i.e. each level is created and built on the basis of the previous one. The first level of sensory integration begins in fetal life and ends at the end of the first year of life. At this stage, the development of sensory bases, i.e. the vestibular, proprioceptive and tactile systems, takes place [6].

The atrial system closely interacts with the sense of sight, hearing, touch and the proprioceptors of muscles and joints [24, 29, 37]. 
Shortening the duration of pregnancy causes that the onset of the first level of sensory integration does not occur under physiological conditions (that is, during fetal life), and the linearity of this phenomenon suggests that disorders of this period will also be visible in subsequent stages, unless actions are taken aimed at compensating this deficit.

Maintaining balance is a multi-faceted phenomenon. It is connected with locomotor efficiency, the shortest response and decision-making time, and the proper orientation of the body in space.

The main role in maintaining balance is played by two basic systems: atrial and proprioceptive. The authors hypothesized that shortening the duration of gestation affects developmental abnormalities in these systems, which may translate into imbalances in premature babies, and the correct balance in children starting primary school can play an important role in their adaptation to school requirements [19].

The aim of the study was to assess the impact of premature birth on the ability to maintain balance in children commencing their school education.

\section{Material and methods}

Based on the Declaration of Helsinki and having obtained approval for the study from the bioethics committee, 59 children aged 6-7 (mean $6.38 \pm 0.73$ ) and born prematurely were included in the study group ( 31 girls and 28 boys). The study was based on purposeful sampling. The criteria for participation were age and the week of pregnancy in which the child was born. Premature children participating in the study were born between 24 and 34 weeks of gestation and were postnatally hospitalized in Św. Jadwigi Królowej Provincial Hospital No. 2 in Rzeszów. The parents were informed about the possibility of participating in the study by mail.

The control group consisted of 61 children born at term, including 28 girls and 33 boys, aged 6-7 (mean age $6.42 \pm 0.58$ ). The children in this group were recruited from the Podkarpackie and Lubelskie voivodships.

In the group of children born prematurely $20.3 \%$ did not have physiotherapy. In the first year of life $37.3 \%$ of children attended physiotherapy and $25.4 \%$ continued it. The remaining $17 \%$ of children had physiotherapy for more than 2 years. Organized physical activities were attended by more than a half of the children. As many as $55.9 \%$ of parents described their children as moderately active, while $35.6 \%$ considered their children hyperactive and $8.5 \%$ thought their children were slow. In this group, $35.6 \%$ of children had visual impairment, while hearing impairment was diagnosed in $1.7 \%$.

The research utilized standardized testing tools - oneleg standing test and one-leg jumping test - as well as an original questionnaire survey. It was a part of the research project "Evaluation of the somatotropic development of high-risk preterm infants aged 6-7 in the context of their functioning in primary school" conducted at the Faculty of Medicine of the University of Rzeszow.

A survey was carried out in the group of premature children. The questionnaire was filled in by the parents and consisted of 21 questions concerning the course of pregnancy, and health and activity of the child. The questionnaire was created specifically for the research project.

The one-leg standing test is a tool for assessing the ability to maintain balance under static conditions. It involves the measurement of the time during which a person is asked to maintain balance standing on one lower limb without any help [3].

\section{The test procedure}

The test was performed alternately for both limbs under visual control. It used the following score scale:

0 - the subject is not able to stand on one leg,

1 - the subject is trying, but must immediately put the foot down on the ground,

2 - the subject is trying and manages to maintain balance from 3 to 6 seconds,

3 - the subject is standing, maintaining balance from 7 to 12 seconds,

4 - the subject is standing, maintaining balance from 13 to 16 seconds,

5 - the subject is standing, maintaining balance from 17 to 20 seconds,

6 - the subject is standing, maintaining balance for more than 20 seconds, the equilibrium is maintained.

The one-leg jumping test involved measuring the time during which the subject was required to maintain the body balance under dynamic conditions jumping on one lower limb without any help. The test was performed alternately for both limbs under visual control. The subjects jumped with their eyes closed. The test consisted in jumping on one lower limb on the toes without moving around. The other lower limb was raised. The child was allowed to begin the test with any limb. The test was interrupted when the child was wobbling, trying to balance with the upper limbs, or lowered the foot to maintain balance [3].

The test used the following score scale:

0 - the subject is not able to jump on one leg,

1 - the subject is trying, performing from 2 to 4 jumps,

2 - the subject is performing from 5 to 8 jumps,

3 - the subject is performing from 9 to 12 jumps,

4 - the subject is performing from 13 to 16 jumps,

5 - the subject is performing from 17 to 20 jumps,

6 - the subject is performing more than 20 jumps, the equilibrium is maintained [3].

The tests performed by prematurely born children were carried out in the period from March 2015 to March 2016 
in the Natural Sciences and Medical Center of Innovative Research in Rzeszow in the presence of the parents. The testing of the control group was conducted in selected primary schools of Podkarpackie and Lubelskie voivodships. The tests were performed with the consent of children, parents and the directors of the facilities. They took place after school classes in one of the available classrooms. The children entered the room and undertook individual fitness tests.

\section{Statistical analysis}

The following tests were used in the statistical analysis: the Shapiro-Wilk test was used to check for the normality of distribution of the analyzed variables. All variables significantly differed from the normal distribution; therefore in the further analysis, the non-parametric Mann-Whitney U-test was used to determine whether there was a statistically significant difference between the two groups in terms of quotient variables, whose distribution differed significantly from the normal one. The results of the fitness tests were converted to a scale of 0-6 for each test and each lower limb separately - the more points, the better the test score. The significance level adopted was $\alpha=0.05$.

\section{Results}

The comparison of children born at term and those born prematurely showed that children born at term had better results in all tests. Table 1 presents a comparative analysis of the fitness test results obtained by children from both groups.

Both in the study group and in the control group, no statistically significant differences were found between the boys and girls in terms of dynamic balance, static balance or the total balance control.

The comparison of the results achieved for the right and left leg in children born at term showed that in terms of static balance and the total balance control, significantly better results were obtained for the right leg than the left one. There was no statistically significant difference between the legs in terms of dynamic balance. The results are shown in Table 2.

Table 1. Comparison of children born at term and children born preterm in terms of the results of fitness tests

\begin{tabular}{lcccc}
\hline \multirow{2}{*}{ Fitness tests } & \multicolumn{2}{c}{ Group } & \multirow{2}{*}{ Mann-Whitney U-test } \\
\cline { 2 - 4 } & Preterm children & Control group & & \\
\cline { 2 - 4 } & Mean \pm SD & Mean \pm SD & Z & p \\
\hline Jumping on the left leg & $3.66 \pm 2.30$ & $5.28 \pm 2.30$ & -3.650 & $<0.001$ \\
Jumping on the right leg & $3.85 \pm 2.24$ & $5.52 \pm 2.24$ & -3.860 & $<0.001$ \\
Jumping on one leg - total (dynamic balance) & $7.51 \pm 4.33$ & $10.80 \pm 4.33$ & -3.707 & $<0.001$ \\
Standing on the left leg with the eyes open & $3.83 \pm 1.62$ & $4.30 \pm 1.62$ & -1.594 & 0.111 \\
Standing on the right leg with the eyes open & $3.85 \pm 1.68$ & $4.90 \pm 1.68$ & -3.359 & 0.001 \\
Standing on one leg with the eyes open - total & $7.68 \pm 2.88$ & $9.20 \pm 2.88$ & -2.899 & 0.004 \\
Standing on the left leg with the eyes closed & $2.12 \pm 0.95$ & $2.74 \pm 0.95$ & -1.715 & 0.086 \\
Standing on the right leg with the eyes closed & $2.07 \pm 0.89$ & $3.33 \pm 0.89$ & -4.556 & $<0.000$ \\
Standing on one leg with the eyes closed - total & $4.19 \pm 1.56$ & $6.07 \pm 1.56$ & -3.285 & 0.001 \\
Standing on one leg - total (static balance) & $15.36 \pm 5.76$ & $18.39 \pm 5.76$ & -2.899 & 0.004 \\
Balance control - total & $19.37 \pm 6.55$ & $26.07 \pm 6.55$ & -5.024 & $<0.001$ \\
\hline
\end{tabular}

Table 2. Comparison of the right and left leg in children born at term in terms of results obtained in fitness tests

\begin{tabular}{|c|c|c|c|c|}
\hline \multirow{3}{*}{ Fitness tests } & \multicolumn{2}{|c|}{ Lower limb } & \multirow{2}{*}{\multicolumn{2}{|c|}{ Mann-Whitney U-test }} \\
\hline & Left & Right & & \\
\hline & Mean \pm SD & Mean \pm SD & $\mathrm{Z}$ & $\mathrm{P}$ \\
\hline Jumps (dynamic balance) & $5.28 \pm 1.02$ & $5.52 \pm 0.74$ & -1.099 & 0.272 \\
\hline Standing with the eyes open & $4.30 \pm 1.38$ & $4.90 \pm 1.34$ & -2.613 & 0.009 \\
\hline Standing with the eyes closed & $2.74 \pm 1.60$ & $3.33 \pm 1.63$ & -2.138 & 0.033 \\
\hline Standing on one leg - total (static balance) & $7.03 \pm 2.69$ & $8.23 \pm 2.72$ & -2.452 & 0.014 \\
\hline Balance control - total & $12.31 \pm 3.14$ & $13.75 \pm 2.96$ & -2.514 & 0.012 \\
\hline
\end{tabular}


In contrast, the comparison of the lower right and left limb in children who were born prematurely showed no statistically significant differences. In other words, the lower right limb does not differ significantly from the left in terms of performance tests.

Figure 1 illustrates the most significant results between study and control groups in static and dynamic balance.

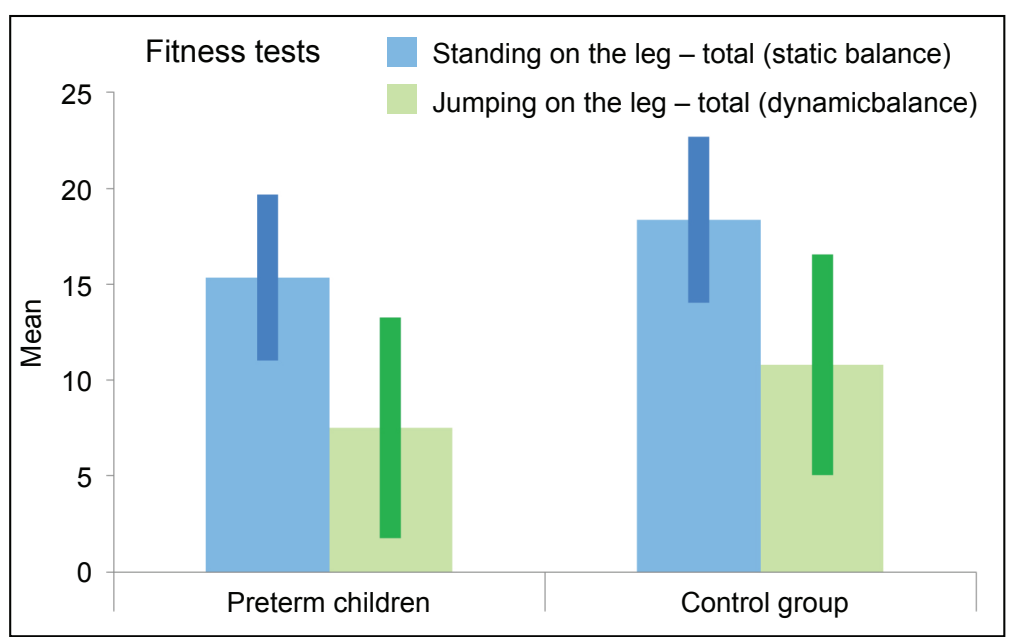

They utilized the test involving standing on one leg in a straight line and on the balance beam with the eyes open and closed. Thirty-one premature children and 20 children born at term were examined. The results showed that children born preterm achieved worse results in the tests compared to the control group. Another study consistent with the present one was documented by Lorefice et al.

[20]. It involved comparing 4-year-olds born prematurely and at term. The authors found that premature children had less control of their body posture and exhibited disorders during static and dynamic balance assessment.

The study mentioned above included a group of children at an age similar to the group qualified for the present study. On the other hand, Husby et al. [17] evaluated the motor skills of persons born preterm and aged 14 and 23. The study showed differences both in terms of fine and gross motor skills. Young adults born prematurely achieved poorer equilibrium-related results than their peers. A meta-analysis by Kievet et al. [8] found that prematurely born children with low birth weight manifested motor

Fig. 1. Graphic illustration of differences between study and control group in static and dynamic balance

\section{Discussion}

Based on the analysis of the study material, it was found that premature children are characterized by lower ability to maintain body balance compared to the control group. Balance control is comparable only for the subjects standing on the left lower limb. The sense of equilibrium is formed from an early age and the course of its development is not linear [36]. Neurological immaturity of preterm babies may favor a delay in the development of certain functions of the body. However, at the age of 2-3, children born prematurely usually compensate for any developmental abnormalities, keeping up with their peers born at term [12]. The vestibular system plays the primary role in children's development. Its proper functioning is manifested in the ability to perform simple and complex motor activities, dealing with the activities of daily living (such as dressing, tying shoes, reading, writing, drawing) $[15,16,17]$. The aspect of equilibrium is an intrinsic part of every activity undertaken. Children born prematurely have problems in their daily functioning $[1,2]$. These may be related, inter alia, to motor disorders, including those affecting the ability to maintain balance.

Numerous publications consistent with the results of our research can be found in the world literature. Eshaghi et al. [11], studying static equilibrium in premature children, used the methodology applied in the present study. development disorders, including balance development delays. Based on these studies, it can be concluded that premature children are not always able to overcome their development problems. This is a good example confirming the fact that the function of body balance control and other motor skills should be continually improved from an early age.

Gender in humans is closely related to sexual dimorphism. There is characteristic diversity in morphological, physiological and mental terms. During pre-school age, one can observe variation in physical activity between boys and girls. Young males prefer activities that require more energy and strength, while females are better at coping with motor skills based on balance and rhythm $[21,22,26]$. However, in our study comparing balance in boys and girls born at term and preterm, no difference was found in the ability to maintain balance control in the conditions of dynamic and static equilibrium according to gender. Our research confirms the results of McEvoy and Grimmer [25], who found that in children aged 5-12, there is no relationship between gender and the extent of angular movement when standing. On the other hand, there are studies showing that sexual dimorphism affects the process of controlling body posture mainly during puberty $[6,13,19,22,26,28,38]$.

Our study, comparing the lower right and left limb in a group of children born prematurely, showed no dominance of one lower limb over the other. In the group of children born at term, dominance of the right leg was observed in terms of static balance and total balance. Regarding dynamic balance, no difference between the legs 
was found, similarly to the group of premature children. Lateralization of the body is expressed through the preference of one side of the body. In the case of upper limbs, right-handed and left-handed people are distinguished, and in the case of lower limbs, we can divide people into rightlegged and left-legged. Researchers believe that the choice of the limb while doing exercises involving motor activity is not accidental [7]. In most people, there is a noticeable functional dominance of the right upper and lower limb. Lateralization in preterm infants is significantly delayed compared to children born at term, and there often occurs unestablished lateralization. The degree of prematurity is also important [9]. The dominance of one side of the body can affect the stabilization process and the distribution of the lower limbs' load in the upright position [32].

\section{The value of the research}

In the study, the ability to maintain balance was determined and compared in girls and boys born prematurely and those born at term. The results indicate the need to develop coordination skills that shape body balance among premature children. It is extremely important to conduct examinations assessing the psychomotor development of premature babies.

A limitation of the study was that the test results presented in the paper are not exhaustive, although they may provide the basis for further research on the ability to maintain the balance of the body. It is worth expanding the research based on the use of specialized diagnostic devices. In future research it would be very interesting to compare the postural stability in the group of patients who did physiotherapy and those who did not.

\section{Conclusions}

1. Children born prematurely have poorer balance control.

2. The ability to maintain balance does not depend on sex.

3. In children born at term, the right lower limb is dominant, while in children born prematurely, neither lower limb is dominant.

Conflict of interest: Authors state no conflict of interest.

\section{References}

1. Anderson P., Doyle L.W., (2003) Victorian Infant Collaborative Study Group. Neurobehavioral outcomes of school-age children born extremely low birth weight or very preterm in the 1990s. JAMA, 289(24): 3264-3272. DOI: $10.1001 /$ jama.289.24.3264.
2. Andersson A.K., Martin L., Brodd K.S., Almqvist L. (2016) Predictors for everyday functioning in preschool children born preterm and at term. Early Hum. Dev., 103: 147-153. DOI: 10.1016/j.earlhumdev.2016.09.011.

3. Ayres J.A. (2012) Południowokalifornijskie Testy Integracji Sensorycznej. Polskie Stowarzyszenie Terapeutów Integracji Sensorycznej, Warszawa.

4. Ayres J.A. (2015) Dziecko a integracja sensoryczna, Wyd. Harmonia.

5. Beck S., Wojdyla D., Say L., Betran A.P., Merialdi M., Requejo J.H., Rubens C., Menon R., Van Look P.F.A. (2010) The worldwide incidence of preterm birth: a systematic review of maternal mortality and morbidity. Bull. World Health Organ., 88(1): 31-38. DOI: 10.1590/ S0042-96862010000100012.

6. Castetbon K., Andreyeva T. (2012) Obesity and motor skills among 4 to 6-year-old children in the United States: Nationally-representative surveys. BMC pediatrics, 12(1): 28. DOI: 10.1186/1471-2431-12-28.

7. Corballis M.C., Badzakova-Trajkov G., Häberling I.S. (2012) Right hand, left brain: genetic and evolutionary bases of cerebral asymmetries for language and manual action. Wiley Interdiscip. Rev.: Cogn. Sci., 3(1): 1-17. DOI: $10.1002 /$ wcs. 158 .

8. de Kieviet J.F., Piek J.P., Aarnoudse-Moens C.S., Oosterlaan J. (2009) Motor development in very preterm and very low-birth-weight children from birth to adolescence: a meta-analysis. Jama, 302(20): 2235-2242. DOI: 10.1001/jama.2009.1708.

9. Dittmar M. (2002) Functional and postural lateral preferences in humans: interrelations and life-span age differences. Hum. Biol., 74(4): 569-585.

10. Dosman C.F., Andrews D., Goulden K.J. (2012) Evidence-based milestone ages as a framework for developmental surveillance. Paediatr. Child Health, 17(10): 561-568.

11. Eshaghi Z., Jafari Z., Jalaie S. (2015) Static balance function in children with a history of preterm birth. Med. J. Islam. Repub. Iran, 29: 310.

12. Fallang B., Hadders-Algra M. (2005) Postural behavior in children born preterm. Neural Plast., 12(2-3): 175-182. DOI: 10.1155/NP.2005.175.

13. Geldhof E., Cardon G., De Bourdeaudhuij I., Danneels L., Coorevits P., Vanderstraeten G., De Clercq D. (2006) Static and dynamic standing balance: test-retest reliability and reference values in 9 to 10 year old children. Eur. J. Pediatr., 165(11): 779-786. DOI: 10.1007/ s00431-006-0173-5.

14. Główny Urząd Statystyczny: http://demografia.stat.gov. $\mathrm{pl} /$ bazademografia/Tables.aspx (22.01.2016).

15. Grabherr L., Macauda G., Lenggenhager B. (2015) The moving history of vestibular stimulation as a therapeutic intervention. Multisens. Res., 28(5-6): 653-687. DOI: 10.1163/22134808-00002495. 
16. Highland Developmental Co-ordination Disorder Group Guidline NOTES, appendix B - terminology http://www. hdcd.org.uk/hdcd_guidance_notes/appendix_b_19.php (25.03.2017).

17. Husby I.M., Skranes J., Olsen A., Brubakk A.M., Evensen K.A.I. (2013) Motor skills at 23years of age in young adults born preterm with very low birth weight. Early Hum. Dev., 89(9): 747-754. DOI: 10.1016/j. earlhumdev.2013.05.009.

18. Kaga K. (1999) Vestibular compensation in infants and children with congenital and acquired vestibular loss in both ears. Int. J. Pediatr. Otorhinolaryngol., 49(3): 215-224. DOI: 10.1016/S0165-5876(99)00206-2.

19. Livesey D., Coleman R., Piek J. (2007) Performance on the Movement Assessment Battery for Children by Australian 3- to 5-year-old children. Child: Care, Health and Development, 33(6): 713-719. DOI: 10.1111/j.1365-2214 .2007.00733.x.

20. Lorefice L.E., Galea M.P., Clark R.A., Doyle L.W., Anderson P.J., Spittle A.J. (2015) Postural control at 4 years in very preterm children compared with term-born peers. Dev. Med. Child Neurol., 57(2): 175-180. DOI: 10.1111/ dmcn.12550.

21. Malina R.M. (2004) Motor development during infancy and early childhood: Overview and suggested directions for research. Int. J. Sport Health Sci., 2: 50-66. DOI: 10.5432/ijshs.2.50.

22. Malina R.M., Bouchard C., Bar-Or O. (2004) Growth, Maturation, and Physical Activity 2-nd edition. Human Kinetics.

23. Marlow N., Wolke D., Bracewell M.A., Samara M. (2005) Neurologic and developmental disability at six years of age after extremely preterm birth. N. Engl. J. Med., 352(1): 9-19. DOI: 10.1056/NEJMoa041367.

24. Massion J. (1998) Postural control systems in developmental perspective. Neurosci. Biobehav. Rev., 22(4): 465-472. DOI: 10.1016/S0149-7634(97)00031-6.

25. McEvoy M.P., Grimmer K. (2005) Reliability of upright posture measurements in primary school children. $B M C$ Musculoskelet. Disord., 6(1): 35. DOI: 10.1186/14712474-6-35.

26. Morris A.M., Williams J.M., Atwater A.E., Wilmore J.H. (1982) Age and sex differences in motor performance of 3 through 6 year old children. Res. Q. Exerc. Sport, 53(3): 214-221. DOI: http://dx.doi.org/10.1080/02701367.1982 .10609342 .

27. Msall M.E., Tremont M.R. (2002) Measuring functional outcomes after prematurity: developmental impact of very low birth weight and extremely low birth weight status on childhood disability. Ment. Retard. Dev. Disabil. Res. Revi., 8(4): 258-272. DOI: 10.1002/mrdd.10046.

28. Nolan L., Grigorenko A., Thorstensson A. (2005) Balance control: sex and age differences in 9- to 16-year- olds. Dev. Med. Child Neurol., 47(7): 449-454. DOI: 10.1111/j.1469-8749.2005.tb01170.x.

29. Nougier V., Bard C., Fleury M., Teasdale N. (1998) Contribution of central and peripheral vision to the regulation of stance: developmental aspects. J. Exp. Child Psychol., 68(3): 202-215. DOI: 10.1006/jecp.1997.2427.

30. O'Connor A.R. (2004) Visual function in low birthweight children. Br. J. Ophthalmol.. 88: 1149-1153. DOI: 10.1136/bjo.2003.035154.

31. O'Connor A.R., Wilson C.M., Fielder A.R. (2007) Ophthalmological problems associated with preterm birth. Eye, 21: 1254-1260. DOI:10.1038/sj.eye.6702838.

32. Önell A. (2000) The vertical ground reaction force for analysis of balance?. Gait Posture, 12(1): 7-13. DOI: http://dx.doi.org/10.1016/S0966-6362(00)00053-9

33. Pollock A.S., Durward B.R., Rowe P.J., Paul J.P. (2000) What is balance?. Clin. Rehabil., 14(4): 402-406. DOI: 10.1191/0269215500cr342oa.

34. Rival C., Ceyte H., Olivier I. (2005) Developmental changes of static standing balance in children. Neurosci. Lett., 376(2): 133-136. DOI: http://dx.doi.org/10.1016/j. neulet.2004.11.042.

35. Sajedi F., Barati H. (2014) The effect of Perceptual Motor Training on Motor Skills of preschool children. Iranian Rehabil. J., 12(1): 14-17.

36. Schmid M., Conforto S., Lopez L., Renzi P., D’Alessio T. (2005) The development of postural strategies in children: a factorial design study. J. Neuroeng. Rehabil., 2(1): 29. DOI: 10.1186/1743-0003-2-29.

37. Steindl R., Kunz K., Schrott-Fischer,A., Scholtz A.W. (2006) Effect of age and sex on maturation of sensory systems and balance control. Dev. Med. Child Neurol., 48(6): 477-482. DOI: 10.1111/j.1469-8749.2006. tb01299.x.

38. Venetsanou F., Kambas A., Aggeloussis N., Serbezis V., Taxildaris K. (2007) Use of the Bruininks-Oseretsky Test of Motor Proficiency for identifying children with motor impairment. Dev. Med. Child Neurol., 49(11): 846-848. DOI: $10.1111 /$ j.1469-8749.2007.00846.x.

39. Winter D.A. (1995) Human balance and posture control during standing and walking. Gait Posture, 3(4): 193-214. DOI: 10.1016/0966-6362(96)82849-9.

40. Wright W.G., Ivanenko Y.P., Gurfinkel V.S. (2012) Foot anatomy specialization for postural sensation and control. J. Neurophysiol., 107(5): 1513-152. DOI: 10.1152/ jn.00256.20.

\section{Received 24.05.2017 \\ Accepted 30.11.2017}

(C) University of Physical Education, Warsaw, Poland 